\title{
Commercialization and Public Good: Conflict, Complement, or Critical Component?
}

\author{
Sandra Schillo
}

\author{
"Andrea: Science knows only one commandment - contribute") \\ to science. [...]
}

Galileo: To what end are you working? Presumably for the principle that science's sole aim must be to lighten the burden of human existence. If the scientists, brought to heel by selfinterested rulers, limit themselves to piling up knowledge for knowledge's sake, then science can be crippled and our new machines will lead to nothing but new impositions.

\author{
Berthold Brecht (1898-1956) \\ Gallileo, Scene 14
}

\begin{abstract}
The controversy regarding the role of science in society - and how science can best achieve its role - may well date as far back as the beginnings of science itself. The specific arguments and the possible mechanisms for science to impact society, however, have changed over time. This article picks up the conversation with regards to the specific role of publicly funded science, presuming, similar to Brecht in this article's opening quotation, that publicly funded science has the goal of making positive contributions to society.
\end{abstract}

To achieve this goal, today's scientists and research managers face a myriad options of publication venues, protection mechanism, and collaborations with external partners including licensing and other options for commercialization. Oftentimes, the goal of achieving positive contributions to society is perceived as being in fundamental conflict with the restrictions many commercialization arrangements place on the use of knowledge. This article argues that, although commercialization may at times conflict with the goal of achieving positive contributions to society, it can also be complementary to pursuits towards societal contributions, or even a critical component in achieving the desired positive contributions to society. More specifically, it suggests that the use of the term "science for the public good" as description of the goal to achieve positive societal contributions might create confusion with the economic term "public good". Thus, it seeks to reframe the discussion of how science can contribute to society in an era of increased openness and interaction.

\section{Introduction}

There are strong expectations that publicly funded science should lead to positive outcomes for society. Oftentimes, these expectations are worded similarly to Deiaco, Hughes, and McKelvey (2012), suggesting that publicly funded research organizations should remain "dedicated exclusively to the creation of public goods for the good of society".
The key argument of this article is that creating public goods does not necessarily lead to the maximization of "the good of society". In fact, the decision to make research outputs available as "public goods" can lead to important research outputs not being utilized at all. For example, if researchers only make their findings available as publicly accessible academic articles, employees of companies would have to read those articles and understand potential implications for their practice in 


\section{Commercialization and Public Good: Conflict, Complement, or Critical Component?} Sandra Schillo

order to be able to use the research results. In some industries, companies follow the academic literature only rarely and such publications are not likely to lead to industry uptake, and subsequent benefits to society. In other industries, companies typically follow the literature, but they know that their competitors are doing the same. If commercialization is expensive in such industries (e.g., in pharmaceutical contexts there are numerous and expensive regulatory procedures), companies may be hesitant to make such investments without some guarantee of exclusive use. Such exclusivity would require patent protection, which generally requires that the original researchers and their institutions apply for such protection before publication. Thus, there are numerous circumstances in which research results will only lead to applications with benefits to society if they are not made publicly available.

This article develops this argument by first discussing the definition and usage of the term "public good", followed by a consideration of commercialization and public good in universities and government laboratories, highlighting the importance of mandates to deliver benefits to society. Then, various examples are provided in which commercialization (i.e., the creation of private benefits) constitutes a conflict, a complement, or even the critical component to delivering benefits to society. Thus, the relationship between commercialization and the creation of societal benefits is shown to be more nuanced than often assumed, and it becomes clear that expertise and careful consideration are required to ensure that societal benefits are indeed maximized, as discussed in the conclusion.

\section{Public Good: Definition and Usage}

There are two fundamentally different definitions of the term "public good", which are both widely used in the context of innovation resulting from publicly funded research. One definition is based on a "common sense" or intuitive interpretation of the term; the other is based on economic terminology.

Common usage refers to the public good as anything that is good for the public, for example activities, services, or products that lead to benefits to citizens or society. The term "public good" is not usually defined explicitly in the academic literature with this connotation (e.g., Heisey \& Adelman, 2011), although the concept is clearly much debated in the context of mandates of public sector organizations and commercialization of research results (Deiaco et al., 2012).
The economic definition opposes public goods and private goods, focusing on two characteristics of goods that relate to their use by others: excludability and rivalry. Excludability refers to the possibility of preventing others from using the good. An item purchased by an individual, for example a computer, can be used by the purchaser, and there is no cost to preventing others from using the item. Rivalry refers to whether the item would be consumed through its use. If an item, such as food, is perfectly rivalrous and "it is consumed by one person, none of it remains for any other" (Hindriks \& Myles, 2006). In this sense, a pure private good is defined as having perfect excludability and rivalry, and a pure public good shows perfect nonexcludability and nonrivalry (Hindriks \& Myles, 2006).

Based on these two characteristics of goods, Table 1 shows that economists also define two related types of goods: club goods and common property resources. This juxtaposition of public and private goods is obviously an abstraction: real goods may not neatly fall into one category.

Public goods, in the economic sense, have been covered extensively in the academic literature, and the distinction between public goods and private goods has been instrumental in explaining why markets are inefficient in providing certain goods, such as basic research or national defence, and why governments therefore need to provide or support the provision of these goods.

In the context of innovation, the market-failure argument underlying most government policy intervention in innovation activities was developed by Arrow (1962). It suggests that, due to the public good nature of many research outputs, markets fail to incentivize companies to invest in research as much as would be optimally required. As stated by Weber and Rohracher (2012):

"The argument is that a fully competitive, decentralized market system will provide a sub-optimal level of investment in knowledge development as a consequence of the public good character of certain types of knowledge, of potential knowledge spill-over effects, and of the short time horizon applied by market actors in their investment decisions."

The flip-side of this market failure is that governments expect social rates of return on investments in research in addition to the private rates of return companies could achieve. There is extensive research (e.g., Griliches, 1958; Mansfield, 1991, Acs et al., 2009) docu- 


\section{Commercialization and Public Good: Conflict, Complement, or Critical Component?} Sandra Schillo

Table 1. Typology of goods, with examples. Adapted from Hindricks and Myles (2006).
Rivalrous
Non-rivalrous

Excludable

\section{Private Good}

Examples: most products, including products incorporating research results, (e.g., computers, cars, medical drugs)

\section{Club Good}

Examples: facilities used by a consortium

\section{Common Property Resource}

Examples: a lake anyone can use for fishing

\section{Public Good}

Examples: published research, data menting the extent to which social returns are achieved, and this argument forms the basis of public investment in research in many countries. (For a detailed discussion, see Bleda \& del Río, 2013).

\section{Relationship between common usage and the economic definition}

In practice, many research outputs are primarily useful to companies. Citizens (i.e., the public) often have limited ability to directly use research outputs, and they instead primarily derive benefits through the activities of companies, which introduce and discontinue products and services, create or reduce jobs, and have positive or negative impact on the environment. Companies typically only have incentives to invest in the development of new products and services if they are able to compete successfully in the market, in other words, if they can derive private returns, in the economic sense.

Therefore, benefits to citizens (i.e., for the public good, in the common sense) often depend on companies successfully using research outputs to create products and services (i.e., private goods, in the economic sense). Hence, there is a seemingly paradoxical situation, where benefits in the public good, in the intuitive sense, only occur if the innovation does not become a public good, in the economic sense.

\section{Publication and Commercialization of Publicly Funded Research}

Government laboratories and universities share the common trait that they are partially funded from public sources. Government laboratories typically are mandate-driven, conducting research in support of policy development or economic activity in specific areas such as health, environment, agriculture, or natural resources, and their research activities can fall anywhere in the spectrum of basic to applied research, or they may even support commercialization activities such as testing and certification. Similarly, universities fulfil a range of roles, such as basic research, teaching, knowledge transfer, and contributing to policy development and economic initiatives (Breznitz \& Feldman, 2012).

For some time now, government laboratories and universities have been under pressure to place greater emphasis on knowledge transfer functions and the creation of commercially relevant intellectual property (Jaffe, 2000; Henderson et al., 1998). One reflection of this trend is the implementation of Bayh-Dole-style legislation (tinyurl.com/4kbt4xx) in many jurisdictions around the world (Kenney \& Patton, 2009; Sampat, 2006). In parallel, academic interest in topics relating to academic entrepreneurship and technology transfer has increased substantially (Perkmann et al., 2013).

Despite much of the motivation of increased commercialization originally deriving from an intent to increase societal benefits, the academic literature has not addressed in depth the relationship between commercialization and societal outcomes (Heisey \& Adelman, 2011, Bozeman, 2000). Researchers have focused on topics such as determinants of university-industry technology and the emergence of spin-off companies (Zucker et al., 2010), intellectual property protection and management (Czarnitzki et al., 2009), and licensing practices (Thursby et al., 2001; Thursby \& Thursby, 2007).

The closest this academic literature has come to addressing the topic of whether the commercialization of the results of academic research increases or decreases 


\section{Commercialization and Public Good: Conflict, Complement, or Critical Component?} Sandra Schillo

benefits to society is in a stream of research on the relationship between publishing and patenting/licensing. Buenstorf's (2009) question, whether research and commercialization are "competing or complementary", is representative of this research, and he highlights key arguments by earlier researchers. Although empirical evidence suggests that researchers who have strong records of patenting also have strong publication records (Buenstorf, 2009), there is some evidence that commercialization activities are associated with reduced public dissemination of knowledge (Campbell et al., 2000; Toole \& Czarnitzki, 2010; Huang \& Murray, 2009; Murray \& Stern, 2007). Thus, the debate with regards to conflict or complementarity is ongoing, and concerns remain that increased commercialization outputs (e.g., patents, licences, royalty revenues) may be detrimental to public good research (Heisey \& Adelman, 2011).

However, public good research in this context refers to research for the benefit of the public, as discussed in the common usage definition above. It does not refer to research outputs as "public goods" (i.e., publications accessible to everyone, an economic public good). Thus, the question should not be whether publications and commercialization are competing or complementary - or, in economic terms, whether research outputs are disseminated as public or private goods. Rather, the question of theoretical and practical consequence is whether the production of public or private goods publications or commercialization - leads to benefits for society.

The following section shows that there is no generalizable answer to this question: any answer depends on the specific research results as well as resources and actors available and accessible in markets and society, whether benefits to the public can be achieved through open publication or whether they require more targeted collaboration with external partners.

\section{Conflict, Complement, or Critical Component: Discussion and Examples}

Although the mechanisms of achieving outcomes of benefit to society are similar for universities and government laboratories, the emphasis on the different mechanisms and the institutional frameworks show some differences. In government laboratories with specific mandates, the link between research activity and anticipated societal outcomes is typically well articulated. For example, ministries of health are expected to contribute to improved health outcomes among cit- izens, environment ministries are tasked with achieving environmental outcomes, and each country tends to cover the various dimensions of societal concerns through a range of ministries and agencies. Although universities and some government research institutions with broader mandates do not usually target such specific mandates, there is an expectation that each discipline of research will contribute to societal outcomes in the manner appropriate to the field.

The following subsections explore the relationship between such societal mandates and commercialization of research results.

\section{Commercialization in conflict with societal benefits}

As noted above, the conflicts described in the academic literature focus primarily on the trade-offs between publishing and patenting or licensing. The key concern here is that researchers may spend their time producing results that are not publicly available, for example, in the form of publications, but rather producing results that benefit individual companies. Although this empirical evidence suggests there is no conflict with regards to publications versus patents or licensing (Buenstorf, 2009; Van Looy et al., 2004), publication output seems to decrease if researchers are involved in startups (Buenstorf, 2009), and collaborations with academics seem to decrease with increasing industry interactions (Clark, 2011).

However, this discussion is more targeted towards a narrow view of considering the immediate research outputs and their characteristics of public good or private good in the economic sense of the term. A discussion of the public good in the common usage sense would consider whether society benefits from the commercialization of research outputs, and more specifically, whether it benefits more than from open publication of research results.

A priori, one might argue that any successful commercialization leads to positive economic outcomes, and the associated social benefits of personal income for staff, potentially health and other benefits for staff, job security, and perhaps associated outcomes such as improved health outcomes (either through health benefits or through the established link between socio-economic status and health outcomes), multiplier effects in the local economy, or perhaps regional economic development. However, it is also possible that commercialization leads to job losses through increased efficiencies, or otherwise deteriorated working conditions. 


\section{Commercialization and Public Good: Conflict, Complement, or Critical Component?} Sandra Schillo

Unfortunately, there is little empirical evidence on this issue, which is also related to the difficulty of measuring societal outcomes and their attribution to specific research contributions. The overall consideration of societal benefits also often requires certain ethical or moral value attributions. For example, the use of research results for governments to increase control over their citizens (e.g., through new software tools aimed at spying on citizens or censoring), the development of advanced weapons, or the adoption of psychological principles to influence voters, can be debated as beneficial or detrimental to society based on political persuasions. At this time, it seems that the approach adopted by many research organizations and funding agencies is to determine publication and patenting record, estimate economic benefits, and then document additional societal benefits through case studies or success stories that demonstrate clearly positive societal outcomes.

As a last comment on the potential conflict between commercialization and public benefits, it should be noted that there are circumstances in which commercialization clearly conflicts with the public interest. Practical experience suggests that such scenarios typically arise out of the failure to negotiate licences and commercialization agreements that protect the interests of the public and the research organization. In many cases, for example, if the right to continue research on the technology is not reserved when an exclusive licence is granted, this shortcoming is attributable to a lack of awareness or human error. Thus, careful attention to the wording of the agreements is warranted (Franza et al., 2012).

\section{Commercialization as complementary to social benefits}

Much of the prior research on publishing and patenting or licensing suggests that the relationship between the dissemination of research results as public goods versus private goods in the economic sense is complementary in nature. Scientists who patent more seem to also publish more (Buenstorf, 2009; Van Looy et al., 2004; Zucker et al., 2002), and researchers engaged in commercialization activities seem to maintain appreciation for open science (Shibayama, 2012), even though the open dissemination of results may be slowed down (Perkmann et al., 2013).

As in the case of research suggesting conflicts, this discussion does not extend to the achievement of societal benefits. However, an optimistic interpretation of the finding that increased patenting and licensing activities coincide with increased research outputs might suggest that whatever societal benefits can be achieved through publishing or patenting will be achieved if researchers pursue both routes.

In addition, much like Chesbrough (2003) suggests in the context of open innovation in companies, public research may lead to results that could be used commercially, but are not within mandated areas of government research organizations (Schillo \& Kinder, 2013) are outside the area interest of university researchers. If such results can be transferred without distracting from other activities with important societal outcomes, additional, complementary benefits to the public or the economy can be achieved through commercialization.

\section{Commercialization as the critical component to creating societal benefits}

Although the two scenarios discussed above - conflict and complement - have been much discussed in the academic literature, this last scenario - commercialization as a critical component to creating social benefits is rarely mentioned. Practice, however, shows that the commercialization of research results, or even the collaboration with private sector partners, is often instrumental in the creation of societal benefits (see Box 1 for examples). There are two key mechanisms for this realization of societal benefits to occur.

First, societal benefits typically arise from the use of products, processes, or services derived from research. For example, pharmaceutical medicines, energy-saving production processes, or water-safety testing services will only lead to improved health or environmental outcomes if they are applied. In fact, the resulting societal benefits will be maximized only if they are applied on a large scale. This application typically implies the involvement of commercial partners, because publicly funded research organizations are usually not mandated to produce products or apply processes on a commercial scale. Even where governments are involved in the provision of services, for example in food or water safety, they usually rely on commercial partners to provide test kits or equipment to conduct the tests. Thus, the benefits resulting from the application of research results can only manifest if they are successfully commercialized. However, note that successful commercialization also implies that companies achieve sustainable profits, either on the sale of the products or services themselves or on the sale of related products and services. Thus, these companies have positive rates 


\section{Commercialization and Public Good: Conflict, Complement, or Critical Component?} Sandra Schillo

Box 1. Societal benefits from interactions between companies and research organizations

In the practice of interactions between companies and research organizations, examples for scenarios in which societal benefits can only be achieved through interactions with companies are extremely common and span most fields and disciplines:

1. A government laboratory requires test kits to ensure food is safe. Constantly arising new food safety threats require new test kits. The agency routinely ranks research requirements according to priorities. Before they are approved, industry partners are identified to ensure the test kits will be developed to commercial scale and can be provided by the commercial partner to the government agency for testing purposes.

2. Researchers develop a method to remove soil contaminants. This method works and is scalable. But, if no company licenses it, the public cannot benefit from it.

3. Researchers discover a new vaccine and publish the results to make sure they are publicly accessible. This action (almost) precludes any company from licensing the vaccine, investing in its approval, and attempting to sell it.

of return; in economic terms, these are private returns to the company. In addition, there are public returns through the widespread use of the research results.

Second, societal benefits can arise indirectly through increased further research outputs derived from collaboration with private sector partners. This scenario has been discussed in the literature. A much-cited study by Van Looy and colleagues (2004) suggests that researchers who engage in entrepreneurial activities also have increased publication output. A similar trend was observed earlier in the seminal work by Zucker, Darby, and co-authors who showed that, in the field of biotechnology, top scientists are both leaders in publications and commercialization (Zucker \& Darby, 2005; Zucker et al., 1998; Darby \& Zucker, 2003; Zucker et al., 1998, 2002). To the extent that products and services based on biotechnology have made positive contributions to society, for example through the development of new medicines or environmental applications, the commercialization of research results can be considered a critical component to the achievement of public health outcomes.

In addition - and this aspect had not been addressed in the literature on technology transfer, either - the trend towards "big data" has made collaborations with private sector companies important to research endeavours in a broad range of fields from computer science, to health sciences, and to social sciences. In this context, academic research and publications are often based on data collected by the private sector, and the resulting research-industry collaborations bring benefits to the private sector players as well as public sector researchers - and by extension hopefully to society through further application of research results.

Thus, research and practice suggests that commercialization may be a critical component to either the immediate delivery of societal benefits, or the creation of new knowledge and research results that may in turn benefit society in the long run.

\section{Comment on Intellectual Property Rights}

Although the above arguments can be made without consideration of intellectual property rights, there is substantial debate on the role of intellectual property in the context of commercialization of publicly funded research. One of the key arguments for strong intellectual property protection is that "in the absence of clearly defined property rights, private firms would not invest in the commercial development and application of the results of federally funded research" (Mowery \& Sampat, 2001). This argument has been countered with the mention of individual technologies that have been commercialized without any assurance of exclusivity. In addition, open innovation business models are showing that the traditional mechanisms of protecting intellectual property to derive commercial benefits are not the only models that can lead to commercial success.

However, even open innovation business models show that: i) companies that openly "give away" some of their intellectual property tend to fiercely guard other intellectual property (e.g., Google's free search service and its closely guarded information on users) and ii) many business models are based on the fact that most 


\section{Commercialization and Public Good: Conflict, Complement, or Critical Component?} Sandra Schillo

end users cannot use the open information without purchasing additional products or services (e.g., open source software companies selling consulting services to customize the software, publishers selling reviews). Thus, intellectual property rights become central to the business model in both open and closed models, but they are perhaps even more important in open models (Chesbrough, 2003), and publicly funded research organizations need to carefully manage their intellectual property rights to achieve the maximum of benefits to society (Schillo \& Kinder, 2013).

\section{Conclusion}

As described in this article, the relationship of commercialization and public benefits as conflict, complement, or critical component has shown that there is very little empirical evidence on the topic. However, this lack of evidence has not prevented policy developers, researchers and the interested public in engaging in this debate over decades (Mowery \& Sampat, 2001).

The article has demonstrated that, in theory, each of the scenarios - conflict, complement, and critical component - is possible and that they do occur in practice. Thus, there is a strong argument to be made for researchers to consider all three scenarios in the design of future studies. In addition, the summary of the limited empirical evidence available shows that most researchers consider the difference between publication and patenting/licensing, and the impact of each on scientific research. Future research should extend this approach and aim to establish the relationship between the different forms of dissemination and societal outcomes.

\section{About the Author}

Sandra Schillo is an Assistant Professor in the Telfer School of Management at the University of Ottawa, Canada. She has worked in and studied the area of science and technology, research and innovation management and entrepreneurship. Her professional work experience includes employment with the National Research Council Canada and the Canadian Food Inspection Agency, and work with Industry Canada in the area of Innovation Policy. She has completed consulting work for Industry Canada, many Canadian Federal Science-based Departments and Agencies, and non-government organisations active in innovation and entrepreneurship. Sandra completed her doctoral studies at the Institute for Entrepreneurship and Innovation Management, University of Kiel, Germany. Her dissertation work focused on spin-off companies. She obtained her Masters' degree in Engineering Management from the University of Karlsruhe, Germany, majoring in corporate strategy and specializing in innovation management and technology transfer. As a consultant, Sandra integrates her experience in research commercialization, her in-depth academic expertise, and her communication skills for the benefit of public and private sector clients. Sandra is fluent in English, French and German, and has working knowledge of Italian. 


\section{Commercialization and Public Good: Conflict, Complement, or Critical Component?}

Sandra Schillo

\section{References}

Acs, Z. J., Braunerhjelm, P., Audretsch, D. B. \& Carlsson, B. 2009. The Knowledge Spillover Theory of Entrepreneurship. Small Business Economics, 32(1): 15-30. http://dx.doi.org/10.1007/s11187-008-9157-3

Bozeman, B. 2000. Technology Transfer and Public Policy: A Review of Research and Theory. Research Policy, 29(4-5): 627-655. http://dx.doi.org/10.1016/S0048-7333(99)00093-1

Bleda, M., \& Del Río, P. 2013. The Market Failure and the Systemic Failure Rationales in Technological Innovation Systems. Research Policy, 42(5):1039-1052.

http://dx.doi.org/10.1016/j.respol.2013.02.008

Breznitz, S., \& Feldman, M. 2012. The Engaged University. The Journal of Technology Transfer, 37(2): 139-157. http://dx.doi.org/10.1007/s10961-010-9183-6

Buenstorf, G. 2009. Is Commercialization Good or Bad for Science? Individual-Level Evidence from the Max Planck Society. Research Policy, 38(2):281-292.

http://dx.doi.org/10.1016/j.respol.2008.11.006

Campbell, E. G., Weissman, J. S., Causino, N., \& Blumenthal, D. 2000. Data Withholding in Academic Medicine: Characteristics of Faculty Denied Access to Research Results and Biomaterials. Research Policy, 29(2): 303-312.

http://dx.doi.org/10.1016/S0048-7333(99)00068-2

Chesbrough, H. W. 2003. Open Innovation: The New Imperative for Creating and Profiting from Technology. Boston: Harvard Business Press.

Clark, B. 2011. Influences and Conflicts of Federal Policies in Academic-Industrial Scientific Collaboration. The Journal of Technology Transfer, 36(5):514-545.

http://dx.doi.org/10.1007/s10961-010-9161-z

Deiaco, E., Hughes, A., \& McKelvey, M. 2012. Universities as Strategic Actors in the Knowledge Economy. Cambridge Journal of Economics, 36(3), 525-541. http://dx.doi.org/10.1093/cje/bes024

Franza, R. M., Grant, K. P., \& Spivey, W. A. 2012. Technology Transfer Contracts between R\&D Labs and Commercial Partners: Choose Your Words Wisely. The Journal of Technology Transfer, 37(4):577587.

http://dx.doi.org/10.1007/s10961-010-9191-6

Griliches, Z. 1958. Research Costs and Social Returns: Hybrid Corn and Related Innovations. The Journal of Political Economy, 66(5):419-431.

http://www.jstor.org/stable/1826669

Heisey, P. W., \& Adelman, S. W. 2011. Research Expenditures, Technology Transfer Activity, and University Licensing Revenue. The Journal of Technology Transfer, 36(1): 38-60. http://dx.doi.org/10.1007/s10961-009-9129-z

Henderson, R., Jaffe, A. B., \& Trajtenberg, M. 1998. Universities as a Source of Commercial Technology: A Detailed Analysis of University Patenting, 1965-1988. Review of Economics and Statistics, 80(1): 119-127.

http://dx.doi.org/10.1162/003465398557221
Hindriks, J., \& Myles, G. D. 2006. Intermediate Public Economics. Cambridge: MIT Press.

Huang, K. G., \& Murray, F. E. 2009. Does Patent Strategy Shape the Long-Run Supply of Public Knowledge? Evidence from Human Genetics. Academy of Management Journal, 52(6): 1193-1221. http://dx.doi.org/10.5465/AMJ.2009.47084665

Jaffe, A. B. 2000. The US Patent System in Transition: Policy Innovation and the Innovation Process. Research Policy, 29(4-5): 531-557. http://dx.doi.org/10.1016/S0048-7333(99)00088-8

Mansfield, E. 1991. Academic Research and Industrial Innovation. Research Policy, 20(1): 1-12. http://dx.doi.org/ 0.1016/0048-7333(91)90080-A

Mowery, D. C., \& Sampat, B. N. 2001. University Patents and Patent Policy Debates in the USA, 1925-1980. Industrial and Corporate Change, 10(3): 781-814. http://dx.doi.org/10.1093/icc/10.3.781

Murray, F. \& Stern, S. 2007. Do Formal Intellectual Property Rights Hinder the Free Flow of Scientific Knowledge?: An Empirical Test of the Anti-Commons Hypothesis. Journal of Economic Behavior \& Organization, 63(4): 648-687.

http://dx.doi.org/10.1016/j.jebo.2006.05.017

Perkmann, M., Tartari, V., McKelvey, M., Autio, E., Broström, A., D’Este, P., Fini, R., Geuna, A., Grimaldi, R., \& Hughes, A. 2013. Academic Engagement and Commercialisation: A Review of the Literature on University-Industry Relations. Research Policy, 42(2): 423-442.

http://dx.doi.org/10.1016/j.respol.2012.09.007

Sampat, B. N. 2006. Patenting and US Academic Research in the 20th Century: The World before and after Bayh-Dole. Research Policy, 35(6): 772-789.

http://dx.doi.org/10.1016/j.respol.2006.04.009

Schillo, R. S., \& Kinder, J. S. 2013. Business Models and Open Innovation: Translating a Business Framework into the Context of Government Laboratories. Presentation to European Group for Organizational Studies (EGOS) Conference, July 5, Montreal, Quebec.

Shibayama, S. 2012. Conflict between Entrepreneurship and Open Science, and the Transition of Scientific Norms. The Journal of Technology Transfer, 37(4): 508-531.

http://dx.doi.org/10.1007/s10961-010-9202-7

Thursby, J. G., Jensen, R., \& Thursby, M. C. 2001. Objectives, Characteristics and Outcomes of University Licensing: A Survey of Major US Universities. The Journal of Technology Transfer, 26(1-2): 59-72. http://dx.doi.org/10.1023/A:1007884111883

Thursby, J. G., \& Thursby, M. C. 2007. University Licensing. Oxford Review of Economic Policy, 23(40): 620-639. http://dx.doi.org/10.1093/oxrep/grm031

Toole, A. A., \& Czarnitzki, D. 2010. Commercializing Science: Is There a University "Brain Drain" from Academic Entrepreneurship? Management Science, 56(9): 1599-1614.

http://dx.doi.org/10.1287/mnsc.1100.1192

Van Looy, B., Ranga, M., Callaert, J., Debackere, K., \& Zimmermann, E. 2004. Combining Entrepreneurial and Scientific Performance in Academia: Towards a Compounded and Reciprocal Matthew-Effect? Research Policy, 33(3): 425-441. http://dx.doi.org/10.1016/j.respol.2003.09.004 


\section{Commercialization and Public Good: Conflict, Complement, or Critical Component?}

\section{Sandra Schillo}

Weber, K. M., \& Rohracher, H. 2012. Legitimizing Research, Technology and Innovation Policies for Transformative Change: Combining Insights from Innovation Systems and Multi-Level Perspective in a Comprehensive 'Failures' Framework. Research Policy, 41(6): 1037-1047.

http://dx.doi.org/10.1016/j.respol.2011.10.015

Zucker, L. G., \& Darby, M. R. 2005. Socio-Economic Impact of Nanoscale Science: Initial Results and Nanobank. National Bureau of Economic Research.
Zucker, L. G., Darby, M. R., \& Armstrong, J. S. 2002. Commercializing Knowledge: University Science, Knowledge Capture, and Firm Performance in Biotechnology. Management Science, 48(1): 138-153. http://dx.doi.org/10.1287/mnsc.48.1.138.14274

Citation: Schillo, S. 2014. Commercialization and Public Good: Conflict, Complement, or Critical Component. Technology Innovation

Management Review, 4(7): 27-35. http://timreview.ca/article/810

Keywords: public good, societal benefits, university research, technology transfer, commercialization, science in society, publicly funded science, intellectual property 